\title{
Rhetorical patterns of argumentation in EFL journals of Persian and English
}

Pishghadam, Reza $\triangle$

Ferdowsi University of Mashhad, Iran (pishghadam@um.ac.ir)

Attaran, Atena

Ferdowsi University of Mashhad, Iran (atena.attaran@gmail.com)

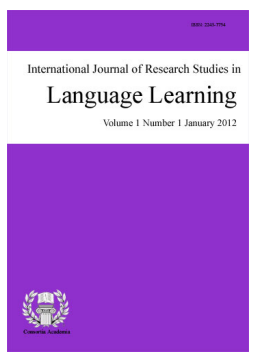

ISSN: 2243-7754 Online ISSN: 2243-7762

OPEN ACCESS

\section{Abstract}

Argumentation is a core of article writing. Despite its importance, no English as a foreign language (EFL) research has examined how Iranian researchers set their argumentations based upon a well-established theoretical model of argumentation. This qualitative study intends to bridge this gap by building upon Toulmin's (2003) model of argumentation to analyze the use of argumentation in EFL articles rhetorically. To this end, 90 articles from the reliable EFL journals in English and Persian were randomly selected with the purpose of discovering underlying conventions which lay behind their argumentations in discussion section of each. Articles in Persian corpus were written by native Persian writers, articles in English corpus were written by native English writers and English articles in inter-language corpus were written by native Persian speakers. This study pointed the differences among the three groups of articles. It was thus indicated that Iranians transfer their first language argumentation rhetorical patterns to their writing in a foreign language, i.e. English. This illustrates that culture may count for the argumentation elements presented in Iranian EFL articles. Other influential factors were also discussed. Finally, pedagogical implications were suggested in the context of second language learning.

Keywords: speech act of argumentation; rhetorical pattern; EFL articles; culture; corpus; language analysis 


\section{Rhetorical patterns of argumentation in EFL journals of Persian and English}

\section{Introduction}

Granted the fact that English language journals lie at the forefront of international databases, the use of languages other than English has declined, and there is a strong tendency for scholars to publish their findings in the most likely language of English (Flowerdew, 1999). Scholars' articles in any language attempt to convince their readers to accept an idea based on logical evidence in defense of their claim. This notion was remarked as argumentation by Toulmin (1958) who asserted that argumentation is a well-grounded claim which stands strongly against criticism.

Argumentative essays specifically and writing in second language generally have provoked a considerable anxiety in EFL students, learners of English as a foreign language, who have not gained intimate knowledge of sequencing their thought pattern (Zhu, 2001). In this regard, contrastive rhetoric was introduced by Kaplan in 1966 as a pedagogical solution to the problem of L2 organizational pattern (Matsuda, 1997). This field of inquiry addressed writing as a reflection of cultural thought patterns (Liao \& Chen, 2009; Xing, Wang, \& Spence, 2008) which might negatively influence writing in a second language (Connor, 1966). This negative rhetorical transfer often leads to an ineffective English L2 writing.

Although the notion of contrastive rhetoric has attracted criticism (Leki, 1997; Spack, 1997; Zamel, 1997), without a shadow of doubt, it has had a considerable effect on the understanding of cultural differences in writing (Connor, 2002) and the need for EFL writers to learn organizing their English written discourse and awareness of English rhetorical patterns still exist. Moreover, the way to fulfill its potential practical application in classrooms is yet to be developed (Matsuda, 1997).

The present study was thus motivated to uncover the underlying rhetorical patterns and strategies utilized in establishing argumentation of EFL articles written by Iranians both in English and Persian and those written by native speakers of English. In fact, this study hopes to shed lights on existing conventions in Persian writing and heighten Iranians' awareness of English underlying thought patterns.

\section{Theoretical Framework}

Introduction of speech act in 1962 by John Austin leaded to assortment of studies in this area among different cultures by which various speech acts were examined for instance, compliment (Wolfson, 1981), suggestion (Barenjee \& Carrell, 1988; Jiang, 2006), complaint (Salmani-Nodoushan, 2007; Young, 2008), apology (Fahey, 2005; Shariati \& Chamani, 2009), criticizing (Min, 2008), and correction (Pishghadam \& Kermanshahi, 2011; Takahashi \& Beebe, 1993) among which argumentation has received scant attention.

Contemporaneous with the introduction of speech act, a great deal of attention has also been devoted to the field of contrastive rhetoric which often addressed expository prose (Jenkins \& Hinds, 1987; Kobayachi, 1984; Ventola \& Mauranen, 1991). And only recently argumentation and persuasion have been studied in contrastive studies (Connor \& Launer, 1988, cited in Connor, 1996). Therefore, this study reviewed the background of current studies of rhetoric on argumentation.

In an early attempt, Choi (1988) analyzed Korean argumentative texts by comparing the structure of argumentative texts of Korean speakers' writing in English with native speakers' writing in Korean and English native speakers' writing in English. She studied 11 essays written by three students on three argumentative topics. The results of the study indicated that in Korean students follow a specific rhetorical pattern neither in their Korean essays nor English ones. However, there was a preferred structure in all English essays, namely claim (thesis statement of the essay) + justification (arguments supporting claim) + conclusion. It was also admitted 
that unlike English essays, the structures of the Korean essays were non-linear.

With reliance on argumentation, Kelly and Bazerman (2003) tried to find out the ways students engaged in scientific reasoning connect general theoretical claims to specific data in constructing evidence. Two highest-rated technical papers of students majoring in oceanography were chosen. The analysis of a successful written text showed that the epistemic level of claims may differ according to rhetorical needs of different sections of genre, e.g., introduction, interpretations, conclusion. Argument followed hierarchical arrangement, that is, key conceptual terms were introduced first. Moreover, sentences within an argument were formed by multiple cohesive links. Finally, sentences at the boundary of sections and subsection were weighed down with cohesive links.

A comparative study of Hirose (2003) investigated the relationship between Japanese learners' L1 and L2 writings. He studied Japanese and English rhetorical patterns of the argumentative essays. In his research, he made a comparison between L1 and L2 compositions in terms of their organizational patterns, organizational scores, and the overall quality of writings. He found that the majority of Japanese students utilized a deductive type of organizational pattern in both L1 and L2 and despite the similarities between L1 and L2organizational patterns, the scores on the L2 compositions did not correlate with L1 organizational scores. He also mentioned that Japanese writers employed a deductive pattern in their L1 more than their L2.

In 2009, Cheng and Chen tried to investigate Taiwanese argumentation skills from contrastive rhetoric perspective. They examined English argumentative writing of Taiwanese students by applying Toulmin model. Besides, they adopt a cross-language and cross-nationality comparison design to broaden the understanding of cultural effects on rhetorical features. To do so, they compared argumentative text of 40 Taiwanese both in Chinese and English and 39 US college students in English. The results of study indicated that Taiwanese students' arguments were less extended and complex, in addition, they displayed a limited range of argumentative structure in comparison to American arguments. However, both Taiwanese and American students are weak at handling oppositional structures, an essential feature discriminating Chinese and English rhetoric. This study also revealed that culture may not be an influential factor for the argument features employed in Taiwanese writing of English as Chinese argumentative texts were partially similar to American ones. L2 language proficiency and developmental factors may play a mediating role in the utilization of argument structures.

Like study of Hirose in 2003, Rashidi and Dastkhezr (2009) compared English and Persian organizational patterns in argumentative writings of Iranians students. The study was carried out within-subject comparisons of 30 undergraduate students of English L1 and L2 compositions in terms of organizational patterns, organization scores, and overall quality. The results revealed that majority of students used deductive type of organizational patterns in both L1 and L2. Although similarities existed between L1 and L2 organizational patterns, L2 organization scores were not significantly correlated with L1 organization scores. Besides, L2 composition total scores differed significantly from those of L1; and some students evidenced problems in organizing both L1 and L2 texts.

In another study Pishghadam and Attaran (in press) showed that proficient L2 users are aware of cultural differences to some extent and try not to let their first language rhetorical pattern interfere their L2 writings. In this regard, researchers compared discussion sections of 90 reliable EFL articles written by native speakers of Persian in their native language and English and those written by native speakers of English. The results revealed that Iranian writers adopted an English-like rhetorical pattern quantitatively though they favor to use backing and qualifier more than their English counterparts.

Although the above studies provide insight into how people of different cultures argue considering rhetorical strategies, there is no accurate picture of how Iranian researchers establish their argumentation. Studies of this field mostly have been carried out on students and there is a dearth of research on researchers who are proficient language users. As a result, the purpose of this study is to examine closely how 1) English researchers employ 
speech act of argumentation in their EFL articles, 2) Iranian researchers benefit from argumentation speech act in their Persian articles, and 3) speech act of argumentation is utilized in English articles written by native speakers of Persian.

\section{Methodology}

Since in this study we aimed at uncovering the underlying rhetorical patterns of argumentation in English, Persian, and Inter-language articles, we tried to find a representative corpus which can fulfill our aim

\subsection{Corpus}

Due to the familiarity of the current authors with the field of English language teaching and learning, 90 articles in this area which were published from 2000 to 2011 were randomly chosen to be studied. These articles were categorized into three groups of 30 as:

$>$ English articles: these articles were written by native speakers of English and chosen randomly amongst the most well-known EFL journals such as, Journal of Applied Linguistics, Journal of Language Learning, and TESOL Quarterly.

$>$ Inter-language articles: It encompassed English articles written by native speakers of Persian. Ferdowsi Reviews, Foreign Language Teaching Journal, and Journal of English Language Teaching and Learning.

$>$ Persian articles: it covered Persian articles written by native speakers of Persian. Journal of Foreign Language Study, Al-Zahra University Journal, and the Journal of Literature and Humanities (Mashhad University).

\subsection{Procedure}

The random selection of 90 articles in the field of English language teaching and learning took the current authors two months to complete. The first 800 words in the discussion section of articles formed the basis of comparison. Afterwards, Toulmin's model of argumentation $(1958,2003)$ was applied like previous works of Lauerbach (2007); Lu, Chiu and Law (2011); Nussbaum (2008); Scholtza, Braund, Hodges, and Koopman (2008). Discarding paragraphs that were ill-formed on the basis of argumentation model, we witnessed three common organizational patterns, which are discussed later.

Toulmin $(1958,2003)$ analyzed argumentation in terms of six functional elements and their relationships: (a) claim, (b) data, (c) warrant, (d) backing, (e) qualifier, and (f) rebuttal by considering every single sentence as a unit of analysis.

Claim: The statement that speaker asks hearer to accept. It is the conclusion to be argued for.

$>$ Data (Ground): It represents facts or the premises drawn upon as the basis for the claim.

$>$ Warrant: It is the bridge to justify how the claim is derived from the data. In fact, it links data and other grounds to the claim.

$>$ Backing: It gives additional support to the warrants.

$>$ Qualifier: It shows the limitation or strength of claim. A qualifier serves as an indication that the claim is not absolute or universal. Modals like probably, perhaps, usually, most, always are applied here.

$>$ Rebuttal: Here is the probable presence of counter-argument. It signifies the conditions which might 
defeat the major claim.

Moreover, as Semitic languages like Persian develop their ideas through parallelism, four main types of parallelism were also considered in both Persian and inter-language paragraphs from contrastive rhetoric perspective:

$>$ Synonymous Parallelism. Thought and phrasing of the first idea are balanced by the second part. Coordinating conjunctions are often used here.

$>$ Synthetic Parallelism. The idea or thought of the first part is completed in the second part. Conjunctive adverbs are welcomed here.

$>\quad$ Antithetic Parallelism. The started idea in the first part is emphasized by expression of contrasting.

$>$ Climactic Parallelism. The idea of a passage is not completed until the very end of the passage (Kaplan, 1966).

\section{Results}

In the following section, to come up with the rhetorical patterns, we analyze some samples of English, Persian, and Inter-language. Considering English paragraphs, they mostly begin with a claim and then the claim is carefully developed by series of data and warrants or other elements of argumentation. Paragraphs may also develop on the reverse procedure by introducing data and warrants at first and then revealing the claim at the end of paragraph.

There was repeated evidence of metaphor emerging within the discourse, or being used as part of hedging sequences to help non-figurative points emerge (Data). Some of the data can be explained in terms of a recently effect, whereby (often peripheral) features of an earlier metaphorical expression triggered a later one (Warrant). The examples also strongly suggested that the speakers were concurrently accessing both literal and metaphorical senses of a word, even where it was a fairly conventional component of a metaphoric idiom (Claim).

Presented data, warrants, and other element of argumentation model in any of these two ways are dominantly contributed to support and development of claim. In both cases the idea flows straightforwardly from the opening sentence to the last sentence. Moreover, all sentences in paragraphs are relevant to the main idea and there is nothing in the paragraphs that does not belong to the central idea.

The analysis of Persian article reveals that Persian paragraphs normally start with a claim, and main elements of argumentation, data, and warrant help the paragraph to develop. It should be noted that data in discussion sections of articles are normally quotations of well-known scholars which entail embedded claims in support of central claim of a paragraph.

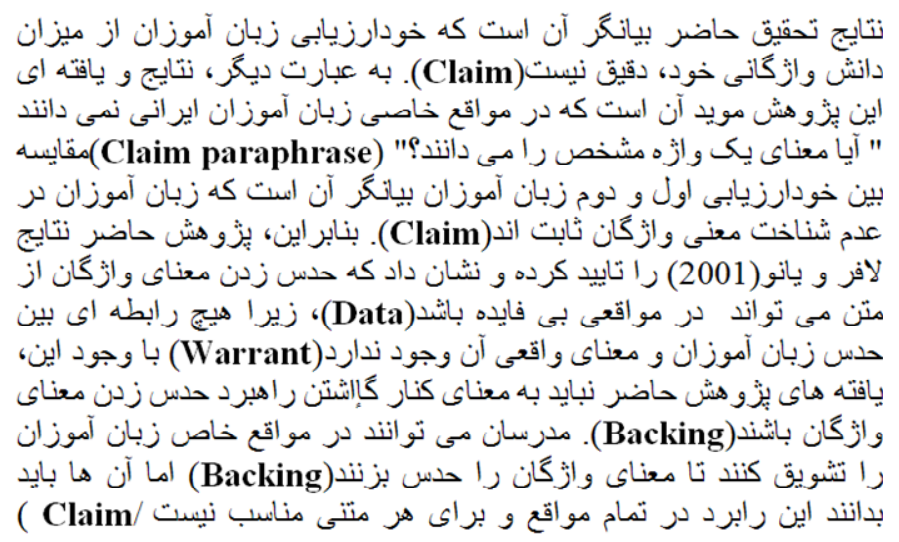

Qualifier) 
Despite parallelism is considered as a means which may hinder direct communication (Kaplan, 1966), synonymous and synthetic parallelisms were mostly observed in Persian paragraphs, for instance the beginning of the third sentence of the paragraph is an example of synthetic parallelism. Its following clause illustrates synonymous parallelism, and the sentence is ended by antithetic parallelism. Intricate parallelisms show not only the flexibility of this language but also its complexity. Among different types of parallelism, synonymous parallelism leads the writer to paraphrase his statements, mostly claim. While Persian paragraphs may seem discursive, they are never digressive. Though parallelism enables Persian writers to discuss different ideas in one paragraph, Persian researchers do not discuss an idea which is irrelevant and unrelated to the central idea of a paragraph.

It is important, however, to mention that this language flexibility encourages the writers to assert more than one claim in their paragraphs. Therefore, a Persian paragraph usually starts with a claim which is deductively supported by data and warrants, and these data and warrants inductively lead the paragraph to another claim at the end of it.

Argumentation in inter-language paragraphs like English ones is formed inductively or deductively with the main focus on one claim.

With respect to creative fluency, we found a significant difference between accuracy and creative fluency and so did between lexical complexity and creative fluency (Warrant). It means that learners with lower lexical complexity have higher creative fluency comparing to learners with higher lexical complexity, and learners with lower accuracy have higher creative fluency than learners with higher accuracy (Claim). This is justifiable since learners who produce more, spend less time on monitoring their product with respect to its accurate structure and correctness (Claim paraphrase). Moreover, in this study, restricted time allotted to each task might be another reason that made learners focus on either the length of their narration or its accuracy (Warrant). Albert and Kormos (2004) also believe that lexical complexity is partially affected by creative fluency but when it comes to accuracy, no influence by creativity has been found (Data).

Although subordination rather than coordination is considered as a degree of style maturity in English, it becomes apparent that most of inter-language sentences are connected coordinately through employment of parallelism. Though this characteristic did occur to form compound sentences in inter-language paragraphs, it was tried not to begin sentences with conjunctions and connectors. However, parallelism, in this case synonymous and antithetic, can be observed within compound sentences.

In a nutshell, the discussed paragraphs can be graphically represented as follow:

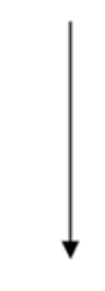

English

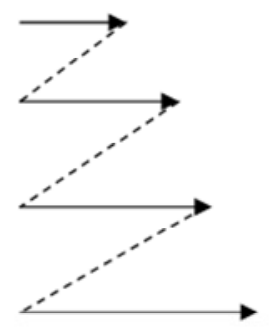

Inter-language

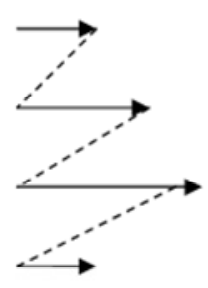

Persian

Figure1. Patterns of written discourse

As it can be seen, sequence of argumentation elements in English paragraphs is straight and linear- data, warrant, and claim are presented respectively. Persian paragraphs do not follow a straight line, mostly two claims are presented in their paragraphs one at the beginning and the other at the end. They try to paraphrase their idea 
and give extra information in each sentence by utilizing parallelism. Therefore, ideas are not presented directly. Besides, sentences are mostly connected by coordination rather than subordination. Inter-language paragraphs like Persian ones enjoy employing parallelism and paraphrasing claim, however, they concentrate on one claim in their paragraphs like the English ones.

\section{Discussion}

This study attempted to dig and delve into the rhetorical patterns of Persian, English, and inter-language argumentation speech act. The three aims of study were, in the first place to explore how English writers set speech act of argumentation in EFL articles, second to analyze the way Persian argumentation is built in EFL articles, and finally to analyze how native speaker of Persian employ speech act of argumentation in their EFL articles.

Regarding the first goal of study, it is concluded that English researchers set their argumentations deductively or inductively in a straightforward manner which is in line with not only the pioneer work of Kaplan (1966) but also with a number of other studies which defined rhetorical characteristics of English as a direct and explicit language (Hind, 1987; Min, 2008; Xing, Wang, \& Spencer, 2008). Among various aspects of cultural differences and their effect on writing, being of low-context cultures encourage English writers to sequence their thought pattern linearly and explicitly (Hall, 1976). Moreover, the utmost importance is attached to product rather than process which may characterize English a writer responsible language (Hinds, 1987).

It is important, however, to note that English language lacks the necessary flexibility, utilization of extensive parallel construction; therefore, claims are stated explicitly and supported directly to communicate clearly which can lessen the risk of probable misunderstandings.

Considering the second goal of the study, we found that, taking both inductive and deductive development in a paragraph makes Persian readers be more responsible than English readers to grasp the main idea of paragraph. Consequently, Persian is considered as a reader responsible language in which some points are left for the readers to infer (Hinds, 1987; Shokouhi \& Baghsiahi, 2010). Persian readers are needed to read between lines and receive covert messages which endorse the concept of high-context culture as well (Hinds, 1987). Being linguistically equipped with different types of parallelism not only makes Persian an implicit language (Allami \& Naeimi, 2010) but also helps its writers to introduce more than one claim within a paragraph deliberately. This flexibility of language calls for more attention to process as well as product. Furthermore, the high-context culture of Iran accents process in Persian paragraphs more than product (Hinds, 1987).

With respect to the third objective, claims are generally welcomed to be paraphrased in inter-language articles which may have some reasons behind. One possibility is that the use of parallelism lets inter-language claims be paraphrased like the Persian ones which can be a sign of L1 to L2 negative transfer. Consequently, through a contrastive rhetoric perspective, culture negatively affects English writing of the Persian writers. Another possibility is that claims are paraphrased conceivably based upon writers' incapability of conveying their thoughts, or a vague picture of the subject being studied and discussed. Disregarding linguistic problems such as misconception of the parts of speech and literal/metaphorical meanings of words, writers' lack of certainty about readers' comprehension leads them to paraphrase their claims. This attitude puts the responsibility on writers more than readers which is a movement toward the English pattern. Whereas native-like responsibility has been exercised, inter-language sentences are mainly connected coordinately which may require more subornation to adopt English-like rhetorical and constructional patterns.

\section{Conclusion}

Although quantitative utilization of argumentation speech act elements among Persian, English, and inter-language articles demonstrates Iranians`application of this speech act in their inter-language articles is on the verge of becoming native-like (Pishghadam \& Ataran, in press), the qualitative aspect of this speech act 
application illustrates inter-language paragraphs are still under the influence of Persian structures and thought patterns. As Sasaki (2000) suggested, there might be a "writing expertise," which is independent of L2 proficiency, affecting L2 writing.

This discussion is not intended to offer any criticism; rather it tries to demonstrate the existing nature of English, Persian, and inter-language paragraph development in EFL articles. Moreover, this research broadens the scope of previous studies with regards to the potential cultural influences on EFL writing. Apart from this, the results also shed more light on the issue that even proficient language users of English as foreign language may still be under the influence of their first language.

The outcomes of the study provide further understanding of Iranian writers' ability in composing argumentative writing which lays considerable emphasis on notifying potential influence of students' culture on their writing. Raising awareness of non-native speakers of English would be extremely helpful and teaching them the writing differences of two cultures especially in academic environment of colleges and universities paves the way for more effective writings as explicit teaching of rhetorical norms of cultures was previously suggested by loads of studies (Copo \& Kalatizis, 1993; Kaplan 1966, 1988; Kubota \& Lehner, 2004). It can also be implied that language teachers are not only responsible to bring students understanding of contrastive grammar and new vocabularies; but they should help learners to grasp ideas and patterns larger than a sentence, moving towards pragmatic outlook on language. Moreover, materials developers can help students of foreign languages to encounter rhetorical aspect of language as well as their syntactical and semantical aspects.

Manifestly, readers must keep in mind that a study such as the present one has its own restrictions. These patterns need to be discovered, uncovered, and compared in other genres of English and Persian to arrive at generalizable rhetorical patterns. To do so, lager samples of different genres are needed to be examined cautiously. Another associated limitation is the lack of comparison between experienced and inexperienced writers of English and Persian, making it impossible to show the significant interaction effect between language and culture.

\section{References:}

Allami, A., \& Naeimi, A. (2010). A cross-linguistic study of refusal: An analysis of pragmatic competence development in Iranian EFL learners. Journal of Pragmatics, 43(1), 385-406. $<$ http://dx.doi.org/10.1016/j.pragma.2010.07.010>

Austin, J. L. (1976). How to do things with words (2nd ed.). New York, NY: Oxford University Press Banerjee, J., \& Carrell, P.L. (1988). Tuck in your shirt, you squid: Suggestions in ESL. Language Learning, 38(3), 313-364. <http://dx.doi.org/10.1111/j.1467-1770.1988.tb00416.x>

Cheng, F., \& Chen, Y. (2009) Taiwanese argumentation skills: Contrastive rhetoric perspective, Taiwan International ESP Journal, 1(1), 23-50.

Choi, Y. H. (1988). Text structure of Korean speakers' argumentative essays n English. Word Englishes, 7(2), 129-142. <http://dx.doi.org/10.1111/j.1467-971X.1988.tb00226.x>

Connor, U. (1966). Contrastive rhetoric: Cross-cultural aspects of second-language writing. Cambridge: Cambridge University Press.

Connor, U. (2002). New directions in contrastive rhetoric. TESOL Quarterly, 36, 493-510. <http://dx.doi.org/10.2307/3588238>

Cope, B., \& Kalantzis, M. (1993). The power of literacy: A genre approach to teaching writing. Philadelphia, PA: University of Pittsburg Press.

Fahey, M. P. (2005). Speech acts as intercultural danger zones: A cross-cultural comparison of the speech act of apologizing in Irish and Chilean soap operas. Intercultural Communication, 8. Retrieved from http://www.Immi.se/intercultural/nr8/palma.html

Flowerdew, J. (1999). Problems in writing for scholarly publication in English: The case of Hong Kong. Journal of Second Language Writing, 17, 243-364. <http://dx.doi.org/10.1016/S1060-3743(99)80116-7> 
Rhetorical patterns of argumentation in EFL journals of Persian and English

Hirose, K. (2003). Comparing L1 and L2 organizational patterns in the argumentative writing of Japanese EFL students. Journal of Second Language Writing, 12, 181-209.

<http://dx.doi.org/10.1016/S1060-3743(03)00015-8>

Hall, E. T. (1976). Beyond culture. New York: Anchor Press/ Doubleday.

Hinds, J. (1987). Reader versus writer responsibility: In U. Connor \& R. B. Kaplan (Eds.), Writing across languages: An analysis of L2 text (pp. 141-152). Reading, MA: Addison-Wesley Publishing Company.

Jiang, X. (2006). Suggestions: What should ESL students know? Elsevier, 34(1), 36-54.

Jenkins, S., \& Hinds, J. (1987). Business letter writing: English, French, and Japanese. TESOL Quarterly, 21, 327-354. <http://dx.doi.org/10.2307/3586738>

Kaplan, R. B. (1966). Cultural thought patterns in intercultural education. Language Learning, 16(1-2), 1-20. <http://dx.doi.org/10.1111/j.1467-1770.1966.tb00804.x>

Kaplan, R. B. (1988). Contrastive rhetoric and second language learning: Notes toward theory of contrastive rhetoric. In A. C. Purves (Ed.), Writing Across Languages and Cultures (pp. 275-304). Newbury Park, CA: Sage Publication.

Kelly, G. J., \& Bazerman, C. (2003). How students argue scientific claims: A rhetorical-semantic analysis. Applied Linguistics, 24 (1), 28-55. <http://dx.doi.org/10.1093/applin/24.1.28>

Kobayashi, H. (1984). Rhetorical patterns in English and Japanese. TESOL Quarterly, 18, 737-738. <http://dx.doi.org/10.2307/3586587>

Kubota, R., \& Lehner. A. (2007). Toward critical contrastive rhetoric. Journal of Second Language Writing, 13, 7-27. <http://dx.doi.org/10.1016/j.jslw.2004.04.003>

Lauerbach, G. (2007). Argumentation in political talk show interviews. Journal of Pragmatics, 39, 1388-1419. <http://dx.doi.org/10.1016/j.pragma.2007.04.004>

Leki, I. (1997). Cross-talk: ESL issues and contrastive rhetoric. In C. Severino, J. C. Guerra, \& J. E. Buutler (Eds.), Writing in multicultural settings (pp. 49-87). New York, N Y: The Modern Language Association of America.

Liao, M., \& Chen, C. (2009). Rhetorical strategies in Chinese and English: A comparison of L1 composition textbooks. Foreign Language Annual, 42(4), 695-720.

$<$ http://dx.doi.org/10.1111/j.1944-9720.2009.01050.x>

Lu, J., Chiu, M. M., \& Law, W. Y. N. (2011). Collaborative argumentation and justification: A statistical discourse analysis of online discussions. Human Behavior, 27, 946-955. $<$ http://dx.doi.org/10.1016/j.chb.2010.11.021>

Matsuda, P. K. (1997). Contrastive rhetoric in context: A dynamic model of L2 writing. Journal of Second Language Writing, 6(1), 45-60. <http://dx.doi.org/10.1016/S1060-3743(97)90005-9>

Min, S. (2008). Study on the differences of speech act of criticism in Chinese and English. US-China Foreign Language, 3, 74-77.

Nussbaum, E. M. (2008). Collaborative discourse, argumentation, and learning: Preface and literature review. Journal of Contemporary Educational Psychology, 33, 345-359. $<$ http://dx.doi.org/10.1016/j.cedpsych.2008.06.001>

Pishghadam, R., \& Attaran. A. (in press). A comparison of articles' argumentation in EFL journals: A case of Persian, English, and EFL speakers, Ferdowsi review.

Pishghadam, R., \& Kermanshahi. P. (2011). Self-correction among Iranian EFL learners: An investigation into their preferences for corrective feedback. Journal of Language Teaching and Research, 2(5), 957-962. $<$ http://dx.doi.org/10.4304/jltr.2.5.957-962>

Rashidi, N., \& Dastkhezr, Z. (2009). A comparison of English and Persian organizational patterns in the argumentative writing of Iranian EFL students. JOLIE, 2(1), 131- 152.

Salmani-Nodoushan, M. A. (2007). Conversational strategies in Farsi complaints: The case of Iranian complainers. Iranian Journal of Language Studies, 2(2), 187-214.

Sasaki, M. (2000). Toward an empirical model of EFL writing processes: An exploratory study. Journal of Second Language Writing, 9(3), 259-291. <http://dx.doi.org/10.1016/S1060-3743(00)00028-X>

Shariati, M., \& Chamani, F. (2009). Apology strategies in Persian. Journal of Pragmatics, 42(6), 1689-1699. 
Pishghadam, R. \& Attaran, A.

$<$ http://dx.doi.org/10.1016/j.pragma.2009.10.007>

Shokouhi, H., \& Baghsiahi, A. T. (2009). Metadiscourse functions in English and Persian sociology articles: A study in contrastive rhetoric. Poznan Studies in Contemporary Linguistics, 45(4), 549-568. $<$ http://dx.doi.org/10.2478/v10010-009-0026-2>

Scholtz, Z., Braund, M., Hodges, M., Koopman, R., \& Lubben, F. (2008). South African teachers' ability to argue: The emergence of inclusive argumentation. International Journal of Educational Development, 28, 21-34. <http://dx.doi.org/10.1016/j.ijedudev.2006.12.005>

Spack, R. (1997). The rhetorical construction of multilingual students. TESOL Quarterly, 31, 765-774. $<\underline{\text { ttp://dx.doi.org/10.2307/3587759> }}$

Takahashi, T., \& Beebe, L. M. (1993). Cross linguistic influence in speech act of correction. In G. Kasper \& S. Bulm-Kulka (Eds.), Interlanguage pragmatics. Oxford: Oxford University Press.

Toulmin, S. (1958). The uses of argument. Cambridge, Uk: Cambridge University Press.

Toulmin, S. (2003). The uses of argument ( $2^{\text {nd }}$ ed.). Cambridge, UK: Cambridge University Press.

Ventola, E., \& Mauranen, A. (1991). Non-native writing and native revising of scientific articles. In E. Ventola (Ed.), Functional and systematic linguistics (p. 457-492). Berlin: Mouton de Gruvter. $<$ http://dx.doi.org/10.1515/9783110883527.457>

Wolfson, N. (1981). Compliments in cross-cultural perspective. TESOL Quarterly, 15(2), 117-124. $<$ http://dx.doi.org/10.2307/3586403>

Xing, M., Wang, J., \& Spencer, K. (2008). Raising students' awareness of cross cultural contrastive rhetoric in English writing via an E-learning. Language Learning and Technology, 12(2), 71-93.

Young, K. D. (2008). A study of complaint strategies for EFL college learners. Modern English Education, 9(2), 58-70.

Zamel, V. (1997). Toward a model of transculturation. TESOL Quarterly, 31, 341-352. $<$ http://dx.doi.org/10.2307/3588050>

Zhu, W. (2001). Performing argumentative writing in English: Difficulties, processes, and strategies. TESL Canada Journal, 19(1), 34-51. 